\title{
Population Structure of Spotted Frogs in the Owyhee Mountains
}

\author{
by \\ Janice C. Engle \\ James C. Munger
}

QL

84.2

.L 352

no. $98-20$

c. 3 
Population Structure of Spotted Frogs in the Owyhee Mountains

\author{
A report on research funded by a challenge \\ cost-share agreement between \\ U.S. Bureau of Land Management and \\ Boise State University
}

\author{
Janice C. Engle \\ James C. Munger \\ Department of Biology \\ Boise State University \\ Boise, ID 83725
}

June 22, 1998 


\title{
Population Structure of Spotted Frogs in the Owyhee Mountains
}

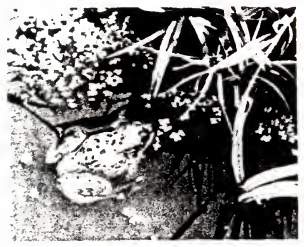

\author{
Interim report from a cost share agreement \\ between \\ Boise State University and \\ The Bureau of Land Management
}

Janice C. Engle and James C. Munger

Department of Biology

Boise State University

\section{Introduction}

Occurring in the Owyhee Mountains of southwestern Idaho is an isolated population of Columbia spotted frogs, Rana luteiventris. This population is part of the portion of this species that is classified by the United States Fish and Wildife Service as a candidate species, that is. listing as threatened or endangered is warranted, but precluded by other higher priority actions.

The long-term outlook for the Owyhee population is unknown. Several BLM surveys (Munger 1994, 1995, 1997, and in prep.) have yielded a substantial number of sites where spotted frogs occur, on the order of 60 populations, including approximately 25 breeding sites. However, these data only provide a snapshot of the present situation--we do not yet know whether spotted frogs are increasing, decreasing, or are stable in numbers. The best way to determine the population trajectory is to conduct long-term (e.g., 20 years) monitoring at a number of sites. There exists a shorter-term alternative to assessing at least some of the factors that determine the long-term viability of a population: assessment of population structure.

Throughout their range, spotted frogs are closely associated with water. In a desert habitat such as is found in the Owyhee Mountains, this association will tend to lead to fragmented populations. A rich literature on the dynamics of metapopulations (e.g.. Gill 1975. Wilcox and Murphy 1985, Hanski 1991, Sjögren 1991, Thomas and Harrison 1992. Stacey and Taper 1992) contains two generalizations: first, smaller subpopulations are more likely to go extinct due to random processes than are large populations. Second, the long-term persistence of a metapopulation consisting of a set of subpopulations will depend on the ability of frogs to colonize one fragment from another and thus "rescue" subpopulations that have gone extinct: the stronger the barriers, the lower the long-term persistence. As an example of these dynamics. Bradford et al. (1993) argued that fragmentation of populations of frogs in the Sierra Nevada by the presence of introduced fish has led to the demise of local subpopulations.

We are pursuing two studies to describe the population structure of spotted frogs. Here we describe preliminary results for one of these studies: the observation of movements of individuals among populations using a combination of intensive marking with PIT (passive integrated transponder) tags and radiotracking. The second study. funded by a BSU faculty grant. will use the study of the genetic structure of spotted frog populations to help understand the metapopulation dynamics of those populations: if subpopulations tend to be genetically disjunct. this would argue that they are isolated and more prone to extinction. If they are genetically similar. this would argue that they are not isolated and under less danger of extinction.

Our goal for the first year was to PIT-tag as many frogs as possible so that over the next two years we could detect movements and assess metapopulation structure. 


\section{Study Site}

We initially concentrated our efforts in two watersheds, Rock Creek and Stoneman Creek/Deep Creek (Figure 1). Both were chosen because they contain one or more known populations of spotted frogs on federal land, they contain substantial amounts of federal land, and they are relatively accessible. To give as complete coverage as possible of the populations, we also attempted to secure permission from private landowners in the two watersheds. We were substantially more successful at obtaining permission in the Rock Creek watershed; we therefore further concentrated our efforts there.

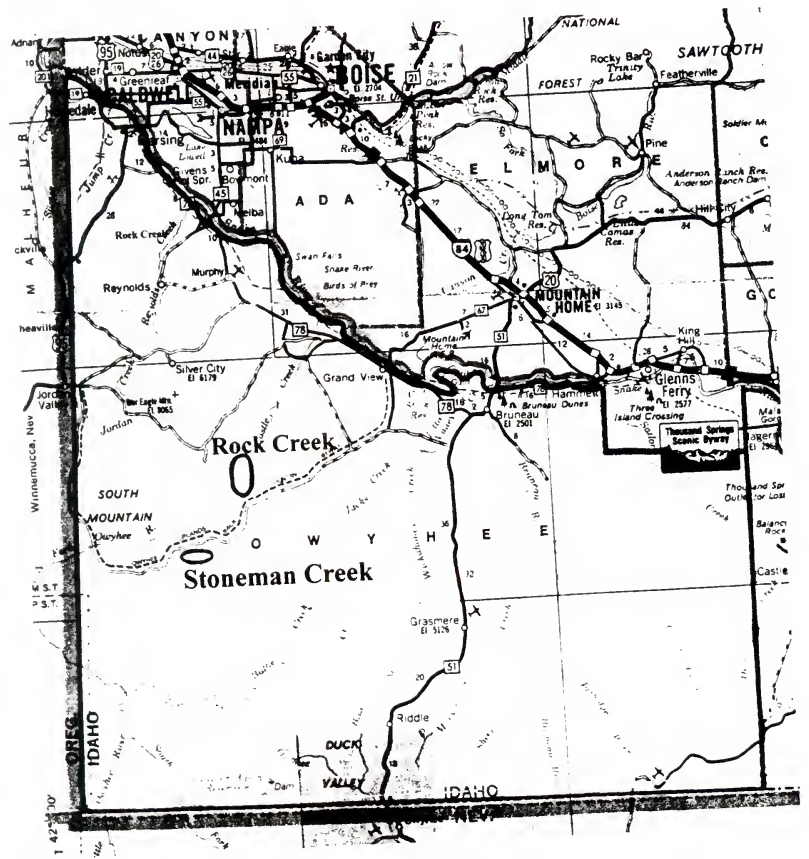

Figure 1. 1997 study area in Owyhee County, Southwest Idaho. 


\section{Materials and Methods}

The study was conducted May through November. 1997 (full-time emphasis from midMay to mid-August). Stream courses and ponds were visually surveyed and spotted frogs were captured by dip-netting. The date and time of each capture was recorded along with the individual's sex (or undistinguishable metamorph or subadult). weight. and snout vent length. A GPS reading of each capture location was recorded and all frogs above $3 \mathrm{~g}$ were PIT-tagged. One toe was clipped from each individual to be used for genetic and skeletochronological analysis. The incision site from the PIT tag and the cut toe were treated with vitamin E to promote healing. The condition of the frog, previous capture brands and unusual characteristics were noted. If an individual frog avoided capture or if a breeding site was confirmed (egg mass or tadpoles present), a GPS reading was taken and the date and time were recorded. Late in the season. newly transformed metamorphs were toe clipped to identify specific natal pond locations.

To determine more specifically the age of individual frogs. skeletochronological analyses are currently in progress. Using a dissecting microscope, the bone is separated from the skin tissue of 500 toe samples. The skin samples are stored in $95 \%$ Ethanol for future genetic analysis. Three hundred sample bones are in various stages of preparation for age analysis and two hundred slides have been completed. The skeletochronological analysis involves the following steps: 1) separation of bone from skin 2) decalcification in a $5 \%$ nitric acid solution for five hours 3 ) preparation of slides: the decalcified phalange bone is sliced into sections 20 microns in thickness. placed on a slide and stained with hematoxylin and 4) analysis of ring structure. Each slide is scanned under $20 \mathrm{x}$ magnification for those sections of the diaphysis that show clear. dark rings. Dark rings represent periods of arrested growth, and have been shown in other species to occur in winter. Thus, we are able to assign an age in winters passed. Up to five representative sections are photographed from each slide and catalogued for future reference (Figure 2).

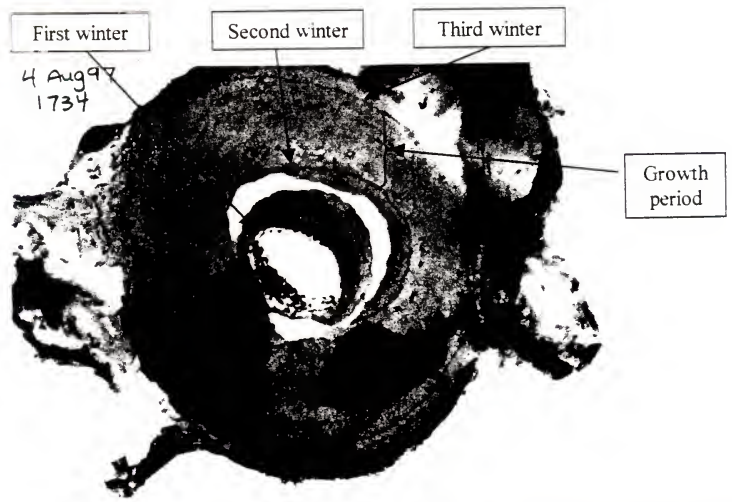

Figure 2. Cross section of the phalange of a three year old male spotted frog. Lines of arrested growth formed during the first three winters of life. with a large growth period occurring during the second summer after transformation. 


\section{Results \& Discussion}

A total of 1073 frogs were observed including captured and uncaptured individuals (Table 1). We PIT-tagged five hundred eighty-nine. toe-clipped 350 metamorphs. and $13+$ frogs avoided capture. Fifty-two of the 66 days of surveying were spent in the Rock Creek area. with the purpose of PIT-tagging as many individuals of this population as possible to improve subsequent recapture numbers and detect movement patterns.

Table 1. 1997 Spotted frog survey focusing mainly on the Rock Creek drainage in the Owyhees.

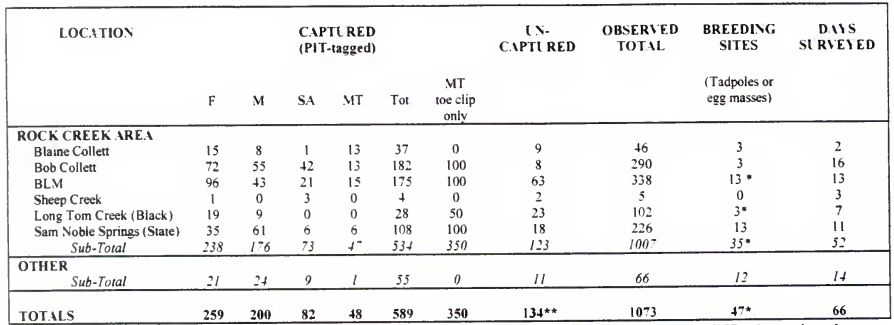

*Tadpoles found continuously along some sections of stream, making specific breeding sites difficult to pinpoint. **20-30 uncaptured frogs observed out of reach, no rover taken.

Within this first season alone, 98 frogs were recaptured (some up to four times) from several hours to three months after their first capture. Of the frogs that were recaptured. most of the movements detected were within 10 meters of the original capture site (Figure 3 ).

\section{Movement by Recaptured Individuals}

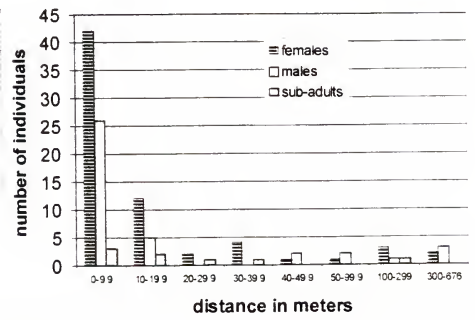

Figure 3. Movement distances for recaptured frogs. 
A closer look at movement over 20 meters (representing a distance greater than most pond widths) showed that both males and females were capable of long distance movement. The greatest distance measured was 675 meters over 5 weeks in early summer by a female in the Rock Creek area (Figure 4). It is unknown whether this movement was along a stream corridor or across less suitable adjacent arid matrix.

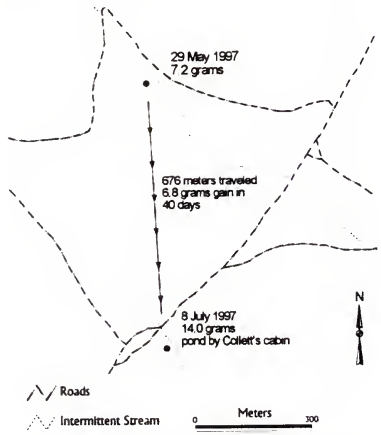

Figure 4. Movement by sub-adult frog as determined by recapture.

Continued monitoring of PIT-tagged individuals will help us to classify where and when individual frogs move throughout the population. For example, as the summer progressed the springs at Sam Noble (which were breeding sites) became isolated by a distance of two hundred meters from the rest of the Rock Creek headwaters. Whether or not this distance constitutes a barrier to dispersal will be monitored very closely next year by a concentrated effort in PIT tagging before and after the corridor dries up. Not only was the water corridor completely dry, but the emergent vegetation had also been grazed and predators (such as sandhill cranes) were observed in areas where frogs had been previously captured. In such areas, the population may fluctuate spatially and temporally between continuous and fragmented.

The probability of recolonization of depleted habitat depends on the ability of individuals to disperse from other parts of the population. Interviews with landowners confirmed one local extinction event in a cattle pond perhaps as a result of the drought of the mid 90's. Three other cattle ponds were observed to have no individuals present during the summer of 1997 , but landowners recall previous frog populations. The first pond became repopulated for at least part of the season in 1997. Whether or not this pond will persist as a breeding and hibernating site will determine if the repopulation event represents a true recolonization of viable habitat or a failed dispersal to unsuitable "sink" habitat.

In several areas of the study, breeding ponds became covered by a thick layer of red Euglena in July. No adult frogs were observed once this occurred and the adults that had been tagged in those ponds were not recaptured elsewhere, despite increased efforts at surveying the adjacent streams. Previous research in the Owyhees indicates that a summer estivation occurs in some individuals; such behavior could explain the disappearance of the frogs in these ponds. Next 
summer, we will schedule surveys of these ponds and their corridors more frequently prior to the Euglena bloom to determine if the frogs are leaving the area.

The summer of 1997 was considered to be relatively wet compared to recent years, so the population characteristics observed are the result of favorable conditions for frogs to breed and move. Early in the summer, the population appeared to be widespread throughout the areas surveyed on Rock Creek (Figure 5 a \& b). Because field observations began after eggs had hatched, the exact location of breeding sites along streams could not be determined. Other breeding sites were clearly affiliated with cattle ponds. The widespread distribution of tadpoles could also be due to increased water flow from spring rains and runoff, causing early dispersal of individuals. Throughout the summer, though, tadpoles were confined to evaporating pools and predation by garter snakes was high. Sections of Rock Creek became totally dry. These conditions are fatal to tadpoles, but are possibly negotiable to adults if the distance is not so great that it is perceived as a barrier to movement. During high water periods, the velocity of the water in Rock Creek through areas of boulders could be prohibitive to movement by the adults unless they go overland.
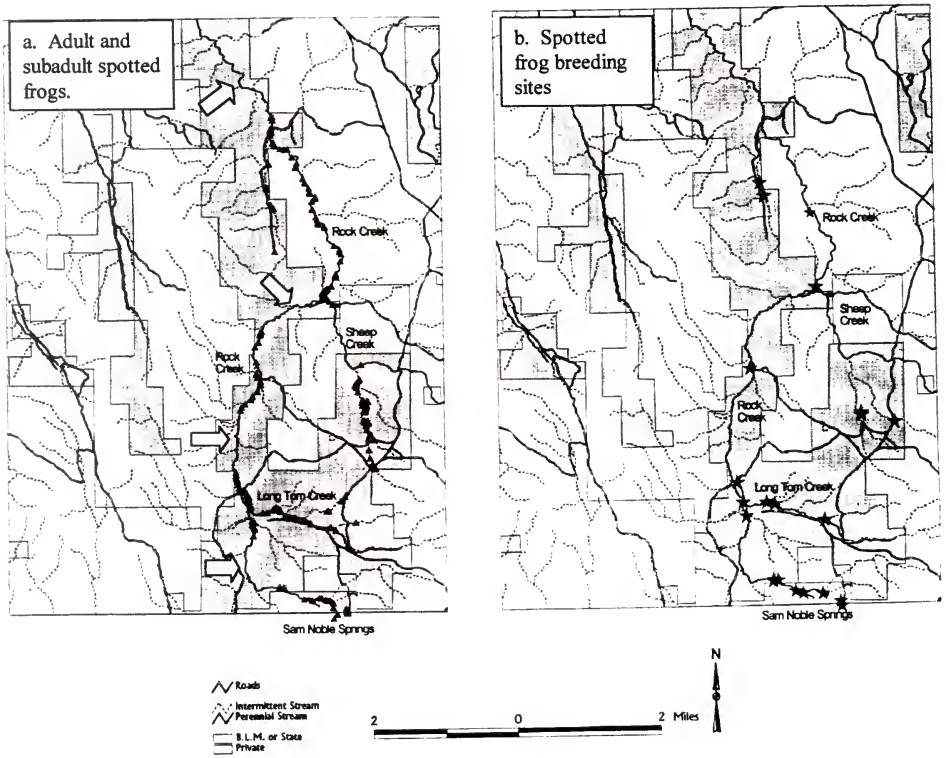

Figure 5. Spotted frog population in the Rock Creek drainage (Hurry Up Creek quadrangle). The sections of stream marked by arrows in 5 a were not surveyed (private ownership, permission denied). 
It is likely that the most common corridors of movement for the spotted frogs are the riparian areas. The 1997 survey shows that all observations were along stream channels and ponds. Most intensive searching was conducted along streams, but no frogs were ever observed away from water when we traveled to and from survey areas. While continued monitoring of these corridors will aid in assessing population connectivity, we will also be searching for the possibility of perpendicular movements across dry land. The Rock Creek area has a potential for this type of movement because of the close proximity of several parallel streams and cattle ponds. It also has landscape features (rocks, ephemeral streams, and uninhabitable water) which could be barriers to the frogs. If the frogs frequently strike out across dry land, exposing themselves to new predators and desiccation, the population could be classified as having a continuous structure. Or, the limiting distance for continuous movement may be calculated by observing the extent to which the frogs leave the riparian corridors and are recaptured in new areas.

\section{Gender Segregation}

On many occasions, we observed that males and females were found grouped by gender. Throughout August, large adult females were almost exclusively found along the dam of a large reservoir. On the other hand, adult males constituted the resident population of Sam Noble Spring pond \#2 (Figure 6a \& b). While surveying Rock Creek, it would be common to find several females and then a group of males along the stream banks. Recapture information in 1998 will be used to determine whether this trend is stable or is caused by cyclic behaviors such as breeding and dispersal.

a. Mostly females at the large reservoir.

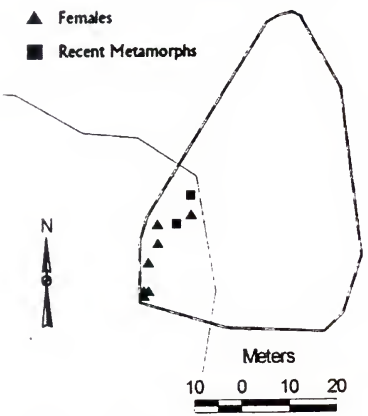

b. Mostly males at Sam Noble pond \#2.

Figure 6. Gender segregation in the Rock Creek drainage. On September 7, there were 9 females (some points overlapping) and no males at the Collett's reservoir (four metamorphs were PITtagged). On July 14, Sam Noble Pond \#2 had 6 females, 25 males and 5 subadults/uncaptured. This trend continued at both locations throughout the season. 


\section{Skeletoch ronology}

Skeletochronological analysis is currently in progress for five hundred 1997 samples. After ages (in winters) are assigned to each individual, population demographics will be tabulated. An understanding of the life span of the spotted frog will provide perspective to the importance of temporal fluctuations in landscape features. The correlation between age and snout vent length will be determined statistically. Preliminary data show that the oldest individual is a 9 year-old female found at the large reservoir. The cohort at Sam Noble pond \#2 is 2-3 year old males.

\section{Plans for 1998}

While 1997 served to delineate the population used for the study, 1998 will be an opportunity to increase the percentage of frogs PIT tagged and recaptured in the area. Early season surveys (April and May) will attempt to identify breeding individuals before they disperse (and, hopefully will help determine if hibernacula and breeding sites are the same). By recording captures earlier in the season, a more complete picture of total movement can be depicted. Likewise, surveys will continue on weekends through the fall when individuals are heading toward overwintering sites. If individuals are observed in areas that are isolated from the rest of the population, radiotransmitters will be used to determine if they negotiate the isolating barrier or remain in the fragmented habitat. Barriers to movement will then be defined (i.e., distance from population and matrix characteristics).

\section{Literature Cited}

Bradford. D., F. Tabatabai, and D. M. Graber. 1993. Isolation of remaining populations of the native frog, Rana mucosa. by fishes in Sequoia and Kings Canyon National Parks. California. Conservation Biology 7(4):882-888.

Gill, D. E. 1978. Effective population size and interdemic migration rates in a metapopulation of the red-spotted newt, Notophthalmus viridescens (Rafinesque). Evolution 32:839-849.

Hanski, I. 1991. Single-species metapopulation dynamics: concepts, models. and observations. Biol. J. Linnean Soc. 42:17-38.

Munger, J., L. Herberger, D. Logan. W. Peterson, L. Mealy, and M. Cauglin. 1994. A survey of the herpetofauna of the Bruneau Resource Area. with focus on the Spotted Frog. Rana pretiosa. Bureau of Land Management Technical Bulletin $\$ 94-7$.

Munger, J.. M. Gerber. M. Cauglin, and T. Bert. 1995. Status and habitat associations of the spotted frog, Rana pretiosa. in Southwestern Idaho. Idaho Bureau of Land Management Technical Bulletin \#96-1.

Munger, J., A. Ames, and B. Bamett. 1997. 1996 Survey for Columbia Spotted Frogs in the Owyhee Mountains of Southwestern Idaho. Idaho Bureau of Land Management Technical Bulletin \#97-13. 
Sjögren, P. 1991. Extinction and isolation gradients in metapopulations: the case of the Pool Frog (Rana lessonae). Biol. J. Linnean Soc. 42:135-147.

Stacey, P. B. and M. Taper. 1992. Environmental variation and the persistence of small populations. Ecological Applications 2:18-29.

Thomas, C. D. and S. Harrison. 1992. Spatial dynamics of a patchily distributed butterfly species. J. Animal Ecology 61:437-446.

Wilcox. B. A. and D. D. Murphy. 1985. Conservation strategy: the effects of fragmentation and extinction. Am. Nat. 125:879-887. 


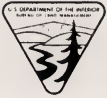

Bureau of Land Management Idaho State Office 1387 S. Vinnell Way

Boise, Idaho 83709 